\title{
Variedades de estados mentais e a teoria do Autoconhecimento de crenças ${ }^{36}$
}

\author{
Varieties of mental states and theories of \\ self-knowledge
}

\section{Robson da Rosa Barcelos}

Doutorando em filosofia na UFSM

Resumo: O presente artigo versa sobre autoconhecimento de crenças. Há vários estados mentais com suas próprias particularidades. Desejos, julgamentos, sensações, emoções e crenças. O foco do artigo é sobre o conhecimento das próprias crenças. O autoconhecimento possui características, a saber, autoridade de primeira pessoa, caráter apriorístico, capacidade cognitivo-discriminativa, infalibilidade, onisciência, assimetria entre a primeira e terceira pessoa e impossibilidade do uso equivocado do pronome "eu" (SILVA FILHO, 2013, p. 33, n. 2). No âmbito cotidiano do senso comum, não há dúvidas acerca da autoatribuição de crenças, porém nem sempre se utiliza corretamente os conceitos, ou seja, há o entendimento incompleto sobre as próprias crenças. Contudo, será que atribuir racionalidade ao agente requer o conhecimento das próprias crenças? Conforme Coliva (2016), há crenças disposicionais e como compromisso. Com relação ao primeiro tipo de crença, o agente não possui responsabilidade epistêmica, já com a segunda sim. Portanto, autoconhecimento de crenças doxásticas enquanto compromisso, requer racionalidade do agente epistêmico, pois há a responsabilidade epistêmica do agente racional.

\footnotetext{
$36 \quad$ O texto em questão é parte modificada da dissertação de mestrado defendida no departamento de filosofia da UFSM.
} 
Palavras-chave: Autoconhecimento; Estados mentais; Crenças.

Abstract: This article deals with self-knowledge of beliefs. There are several mental states with their own peculiarities. Desires, judgments, feelings, emotions and beliefs. The focus of the article is on the knowledge of one's beliefs. Self-knowledge has characteristics, namely, first-person authority, aprioristic character, cognitive-discriminative capacity, infallibility, omniscience, asymmetry between the first and third person and impossibility of misuse of the pronoun "I" (SILVA FILHO, 2013, p. 33, n.2). In the everyday realm of common sense, there is no doubt about the self-attribution of beliefs, but concepts are not always used correctly, that is, there is an incomplete understanding of one's beliefs. However, does attributing rationality to the agent require knowledge of one's beliefs? According to Coliva (2016), there are dispositional beliefs and as commitment. With respect to the first type of belief, the agent has no epistemic responsibility, with the second yes. Therefore, self-knowledge of doxastic beliefs as commitment requires rationality of the epistemic agent, because there is the epistemic responsibility of the rational agent.

Keywords: Self-knowledge; Mental states; Beliefs.

\section{Introdução}

TSualmente, afirma-se o agente epistêmico possui pensamentos e crenças, tais como: estou escrevendo no computador, estou atualizando meu perfil no facebook, acredito que irá haver uma terceira guerra mundial, etc. Isso sugere o conhecimento, ou ao menos o acesso (ou no mínimo a consciência) ${ }^{37}$ das próprias crenças e pensamentos. Dessa forma, a questão é a seguinte: será que atribuir racionalidade aos seres humanos requer o conhecimento das próprias crenças?

Essa questão pode levar respostas bastante significativas sobre a ação humana. Se sim, então o fato de ser racional requer o fato conhecer os próprios estados mentais doxásticos. Por conseguinte, então há as capacidades de agir e de racioci-

$37 \quad$ Esse ponto será melhor esclarecido com a distinção entre autoconsciência e autoconhecimento de Gertler (2011, p.2) no tópico "Questões terminológicas" deste artigo na página 110 . 
nar embasadas no conhecimento dos próprios estados mentais doxásticos, isto é, no autoconhecimento das próprias crenças.

Para melhor compreender o autoconhecimento de crenças, faz mister esclarecer que há diversos tipos de estados mentais, tais como sensações, percepções, crenças, desejos e emoções. No entanto, o foco do presente artigo se concentra na relação entre conhecimento das próprias crenças e racionalidade, compreendida no seu uso cotidiano, na vida ordinária do agente epistêmico. Para tanto, é importante tornar tácito as caraterísticas do autoconhecimento de crenças e suas diferenças para com outros estados mentais.

\section{As crenças e os outros tipos de estados mentais}

As principais variedades de estados mentais podem ser observadas através do seguinte exemplo:

Suponha que eu saia pela porta da frente e pare na metade do caminho em direção ao meu carro, pois percebo que está frio e úmido, que há nuvens escuras e que o vento parece estar aumentando; eu decido que provavelmente irá chover e esfriar, de modo que eu volto para casa para buscar um casaco e um guarda-chuva; tendo feito isso, vou ao carro novamente. Aqui temos vários estados mentais: sensações de frio, umidade, escuridão e tempo ventoso; crenças perceptivas sobre tudo isso e ainda a crença de que vai chover e esfriar; e supostamente um desejo de não me molhar ou sentir frio. Há também vários estados físicos ou materiais: além da condição física do meu ambiente, há o comportamento físico do meu corpo andando, parando, virando a cabeça e andando outra vez, juntamente com a condição física do meu corpo e dos vários órgãos sensoriais: o frio e a umidade da minha pele, as ondas de luz atingindo meus olhos, e assim por diante. (BONJOUR; BAKER, 2010, p. 199)

A partir deste exemplo, pode-se extrair uma lista de estados mentais classificados como sensações, as quais estão relacionadas ao corpo (cf. MASLIN, 2009), ou seja, sensações, as quais proporciona experiência ${ }^{38}$ passiva sobre o próprio en-

$38 \quad$ Uma concepção de experiência é a seguinte: "A experiência é o aspecto qualitativo dos estados mentais que você está tendo agora. A experiência é o que a maioria dos filósofos tem em mente quando falam sobre consciência. No meu uso, toda experiência é experiência consciente. Enquanto alguns que 
torno com relação ao próprio corpo: sensação de frio, de calor, de prazer, de dor. Também se encontra, na citação acima, exemplos de crenças perceptuais, tais como: "eu creio que está chovendo", "eu creio que a chuva resfria o ambiente". Há ainda estados mentais conativos, por exemplo: "eu desejo que pare de chover"; estados emocionais, tais como: "eu estou com medo de me molhar"; outros estados mentais, como: "eu imagino que irá chover". Por fim, há estados mentais ativos, os quais deliberadamente são formados, como os julgamentos. Por exemplo: "eu julgo que a chuva é boa".

Conforme os exemplos acima, os estados mentais podem ser classificados como: sensações, crenças, desejos (estados conativos), emoções, cognições, percepções, imaginações (estado quasi-perceptual) e julgamentos. Cabe salientar que o tipo de estado mental abordado no presente estudo são as crenças, pois se denota importante a relação que os agentes epistêmicos tem com as crenças de si mesmos e do seu entorno. Portanto, minimamente se demonstrou a variedade dos estados mentais com suas características, porém não pretende esgotar a discussão, somente se pontuou algumas peculiaridades, dentre elas as do estado mental do tipo crença.

\section{Questões terminológicas}

Na presente seção, abordar-se-á acerca da intencionalidade, presente em alguns estados mentais e ausente em outros, assim como a diferença entre autoconsciência e autoconhecimento. Salienta-se também que a compreensão de autoconhecimento típica desta investigação não versa sobre autoajuda, nem sobre o conhecimento de traços de caráter. Por fim, se diferencia um possível "eu" de seus estados mentais.

Além da autoatribuição de estados mentais do tipo crença, também ocorre a autoatribuição de diversos tipos de pensa-

usam o termo experiência têm em mente a sensação (por exemplo, a dor) e a percepção (por exemplo, aquela árvore ali), a experiência, como uso o termo, pode tomar como objeto intencional coisas como pensamento, memória e outros conteúdos mentais. Desta forma, a experiência pode ser tanto cognitiva quanto sensorial." (KLEIN, 2015, p. 5). 
mentos. As categorias podem ser desejos, sensações e emoções. Isso, em contexto filosófico, pode ser denominado "atribuição de estados mentais doxásticos" ou "atitudes proposicionais":

Que tipo de nome devemos dar a verbos como "acreditar" e "desejar" e assim por diante? Minha inclinação é chamá-los "verbos proposicionais". Esse é apenas um nome sugerido por conveniência, porque eles são verbos que têm a forma de relacionar um objeto a uma proposição. Como eu tenho explicado, isto não é o que eles realmente fazem, mas é conveniente chamá-los verbos proposicionais. É claro, você pode chamá-los de "atitudes", mas eu não gosto disso porque este é um termo psicológico, e embora todas as instâncias de nossa experiência sejam psicológicas, não há razão para supor que todos os verbos de que estou tratando sejam psicológicos. (RUSSELL, 2009, p. 103)

Desta forma, a utilização do termo "atitude proposicional" para uma classe de estados mentais é detentora de duas características, a saber: a intencionalidade e a forma lógica proposicional (cf. OLIVEIRA, 2014, p. 35).

O termo "intencionalidade" não é utilizado no sentido de intenção. No presente contexto, o termo "intencionalidade" é empregado com o significado dos estados mentais serem sobre alguma coisa. Por exemplo, se o agente crê que o time de futebol brasileiro Internacional será rebaixado para a segunda divisão, a crença é sobre alguma coisa, ou seja, possui um objeto intencional, e este objeto intencional é o time de futebol Internacional. Cabe ressaltar que há estados mentais doxásticos que não possuem objetos intencionais, por exemplo, a vontade de comer (cf. OLIVEIRA, 2014, p. 36).

Outra característica acerca das atitudes proposicionais é a forma lógica proposicional, ou seja, seu conteúdo, formal de uma proposição, pode ser semanticamente avaliado como verdadeiro ou falso. Desta maneira, os estados mentais doxásticos, além de possuírem intencionalidade, também possuem conteúdo proposicional avaliável em verdadeiro ou falso. Portanto, "Uma atitude proposicional é, então, o estado mental de ter alguma atitude, postura, perspectiva ou opinião sobre uma proposição ou sobre o estado potencial de coisas em que essa proposição é verdadeira (...)." (SCHWITZGEBEL, 2015, p. 1). 
Autoconhecimento não é necessariamente o mesmo que autoconsciência. Autoconhecimento é a reflexão é acerca das próprias crenças, às quais podem ser das mais diversas, por exemplo, quando o agente for questionado sobre sua crença na existência de uma terceira guerra mundial, ele responda com conhecimento de si. Ou será que ele tem mera consciência de si? Neste ponto, faz-se importante realizar uma distinção entre autoconhecimento e autoconsciência. Segundo Gertler,

Autoconhecimento é o conhecimento de seus próprios estados mentais - por exemplo, o conhecimento de suas próprias experiências, pensamentos, crenças ou desejos atuais. Autoconsciência é a capacidade de identificar-se (o "eu"), e se distinguir de outras coisas. (GERTLER, 2011, p. 2)

Conforme Gertler, o termo autoconhecimento designa o conhecimento que um "eu" tem dos seus estados mentais, e o termo autoconsciência designa o conhecimento que este "eu" tem ou teria desta coisa ou substância que é o "eu" enquanto algo separado ou ao menos de outros estados mentais ou corporais $^{39}$. O conhecimento dos estados mentais é o conhecimento de propriedades do "eu", ou seja, o autoconhecimento se ocupa na identificação dos estados mentais e seus conteúdos. Já a autoconsciência se ocupa em "como essa referência é alcançada e como se concebe, basicamente, o eu." (GERTLER, 2011, p. 8).

$39 \quad$ A distinção entre o eu e o seu pensamento é elucidado na seguinte passagem: "7. Mas eu, o que sou eu, agora que suponho que há alguém que é extremamente poderoso e, se ouso dizê-lo, malicioso e ardiloso, que emprega todas as suas forças e toda a sua indústria em enganar-me? (...) Passemos, pois, aos atributos da alma e vejamos se há alguns que existam em mim. (...) Um outro é pensar; e verifico aqui que o pensamento é um atributo que me pertence; só ele não pode ser separado de mim. (...) Nada admito agora que não seja necessariamente verdadeiro: nada sou, pois, falando precisamente, senão uma coisa que pensa, isto é, um espírito, um entendimento ou uma razão, que são termos cuja significação me era anteriormente desconhecida. Ora, eu sou uma coisa verdadeira e verdadeiramente existente; mas que coisa? Já o disse: uma coisa que pensa. E que mais? Excitarei ainda minha imaginação para procurar saber se não sou algo mais. Eu não sou essa reunião de membros que se chama o corpo humano; não sou um ar tênue e penetrante, disseminado por todos esses membros; não sou um vento, um sopro, um vapor, nem algo que posso fingir e imaginar, posto que supus que tudo isso não era nada e que, sem mudar essa suposição, verifico que não deixo de estar seguro de que sou alguma coisa." (DESCARTES, 1983, p. 93). 
Desta forma, a identificação do "eu" com o conteúdo do estado mental não é escopo da autoconsciência. Pois, sua ocupação tem um caráter de identificação do sujeito, ou seja, identidade pessoal, de como o sujeito faz referência a si mesmo. A autoconsciência e a identidade pessoal não são assunto deste artigo.

Autoconhecimento não se ocupa em conhecer os traços de caráter. Mas apenas do conhecimento mais "pobre" das próprias crenças:

(...) não são essas as atitudes (se prefiro baunilha ou chocolate) com as quais mais me importo - ou pelo menos elas não são as mais relevantes para o meu autoconhecimento no sentido moralmente impregnado de "autoconhecimento" da recomendação do oráculo de Delfos: "conhece-te a ti mesmo". Supostamente o oráculo não estava interessado no coeficiente de conhecimento que as pessoas têm de suas atitudes em relação ao tempo que faz na Califórnia no mês de abril. À medida que a injunção "conhece-te a ti mesmo" pertence ao autoconhecimento de atitudes, devem ser atitudes como os nossos valores centrais e seus pressupostos fundamentais sobre o mundo e sobre outras pessoas. E sobre tais assuntos, eu acredito (eu acho que acredito!) o nosso autoconhecimento é bastante pobre. (SCHWITZGEBEL, 2012, p. 191).

Dessa forma, o autoconhecimento do presente artigo versa sobre o conhecimento das próprias atitudes proposicionais especificamente do tipo crença. Para adentrar na explicação sobre o caráter, ou valores fundamentais das pessoas, demandaria muito mais do que somente o autoconhecimento das crenças, pois há as emoções, desejos e julgamentos a serem investigados.

Retorna-se à questão do self. Suponha que, o agente esta sentado na frente do computador pensando em quais palavras escrever para que seja bem compreendido. As duas propriedades (estar sentado frente ao computador e buscar as melhores palavras) são do agente ou do "eu" do agente? Observe que existem dois pontos a serem distinguidos, a saber, os estados mentais e/ou corporais do agente, e o "eu" do agente. Com isso, ao afirmar que ele possui propriedades, significa dizer que há uma substância que possui propriedades, ou seja, há um "eu" pensante, que produz ou sofre pensamentos, estados mentais e/ou corporais, os quais individualizam o agente. Des- 
sa maneira, o agente é conhecido somente pelas suas propriedades, a saber seus estados mentais e/ou corporais, ou seja, a concepção de self fica restrita ao acesso a esses estados mentais e/ou corporais. Pois, segundo Hume,

(...) penetro mais intimamente naquilo que denomino meu eu, sempre deparo com uma ou outra percepção particular, de calor ou frio, luz ou sombra, amor ou ódio, dor ou prazer. Nunca apreendo a mim mesmo, em momento algum, sem uma percepção, e nunca consigo observar nada que não seja uma percepção. (HUME 2009, livro 1, parte 4, seção 6, $\S 3$, p. 284)

Dessa forma, percebe-se a problemática envolvida acerca daquilo que se denomina "eu", e os estados mentais e/ou corporais decorrentes desse self. Isso salienta o reconhecimento da problemática da identidade pessoal, entretanto não abordará o importante problema filosófico. Pois, o autoconhecimento se concentra no conhecimento que esse "eu" tem das suas próprias crenças.

\section{Atribuição de crenças}

A autoatribuição de crenças, quanto a atribuição de crenças aos outros, permite uma possível compreensão dos comportamentos e ações dos outros e de si mesmo. Por exemplo, em um experimento realizado por Senju (et al., 2011) no qual se estudou dois grupos de bebês, o grupo A tinha sua visão gentilmente bloqueada por uma venda, a qual fornecia uma experiência visual opaca. O grupo B vestia uma venda bastante transparente. Os bebês de ambos os grupos assistiram um vídeo no qual um ator na respectiva situação de cada grupo tenta encontrar uma caixa, a qual era movida por um fantoche. Assim, após ser retirada a venda dos bebês, e eles observarem o vídeo do ator, novamente, os bebês que tiveram sua visão opaca (grupo A) apresentaram a expectativa de que o ator vendado não encontrasse a caixa na esquerda, já o outro grupo não criou tais expectativas. Dessa forma,

(...) os bebês no presente estudo codificaram que o ator poderia ou não ver o deslocamento do objeto quando ela usava 
a venda, e os bebês foram capazes de usar essa informação para antecipar corretamente o comportamento futuro do ator. (SENJU et al., 2011, p. 880)

Conforme os resultados obtidos por Senju (2011), no início da vida já há indícios da atribuição de estados mentais às outras pessoas, na expectativa de entender as ações e comportamentos dos outros. Essa habilidade genuína de atribuir estados mentais precoces de crença, por parte dos bebês, se inicia pelo menos aos dezoito meses de vida (cf. SENJU et al., 2011, p. 880).

Atribuir estados mentais a si mesmos e às outros não necessita ser algo que só pode ser descoberto por um rigoroso procedimento científico. Ao contrário, trata-se de algo bastante comum e corriqueiro. Por exemplo: quando um cliente levanta a mão num bar (ação), isso se explica porque ele quer chamar o garçom (estado mental atribuído); um motorista move seus braços para girar o volante (ação), o que se explica porque ele quer fazer a curva (estado mental atribuído) etc. Dessa maneira, frequentemente atribuímos estados mentais a nós mesmos e aos outros. Contudo, cabe destacar algumas distinções importantes para a investigação, as quais seguem na próxima seção.

\section{Acesso privilegiado e a visão do senso comum acer- ca do autoconhecimento}

O conhecimento dos próprios estados mentais é um tema complexo. Contudo, indivíduos partilham o senso comum, algumas intuições sobre a capacidade que cada um tem autoconhecimento sobre os próprios estados mentais. Essas intuições, embora sejam problemáticas, mostram um ponto de partida natural para a investigação do modo como cada um conhece as próprias crenças, por exemplo, que cada pessoa tem acesso privilegiado as próprias crenças. Dessa maneira, a discussão do conhecimento das próprias crenças parte de conceitos, teses e teorias - ainda que o senso comum não empregue os termos técnicos típicos da filosofia para denotar tais ideias. 
$\mathrm{O}$ acesso privilegiado de cada um às próprias crenças decorre da assimetria entre a primeira e terceira pessoa. Acesso privilegiado é a característica de ter ciência dos próprios estados mentais única e restrita ao agente, no autoconhecimento de crenças há uma diferença entre o modo como o eu acessa os próprios estados e conteúdos mentais, por meio de método não disponível às outras pessoas. O acesso de terceiros aos meus estados mentais também não está disponíveis para terceiros, pois os outros precisam observar ações e interpretar palavras para então interpretar ou inferir o que outro acredita.

Suponha, que ocorra uma expressão verbal de autoatribuição de uma crença, por exemplo, "acredito que estou escrevendo em meu notebook e escutando uma música". Como é que o ouvinte poderia saber que o agente da autoatribuição da crença, de fato acredita nisso? Ele teria que fazer o que se faz tipicamente ao se obter conhecimento via testemunho. Ou seja, nesse exemplo, a crença é conhecida por uma terceira pessoa por meio de um acesso observacional aos sons da fala da primeira pessoa. Essa mesma crença, no entanto, aparentemente não precisa ser apresentada para a primeira pessoa que se auto atribui um estado mental de crença através de órgãos do sentidos para ser notada. Ou seja, ao contrário da terceira pessoa, "não necessito ouvir ou ler minhas palavras, nem mesmo observar meus comportamentos para saber que esses são meus pensamentos, crenças, desejos, etc." (SILVA FILHO, 2013, p. 17). Logo, é razoável afirmar que a primeira pessoa possui um certo tipo de acesso privilegiado às próprias crenças. Ou seja, a primeira pessoa só sabe o que a terceira pessoa pensa e crê via observação do comportamento motor e verbal da terceira pessoa. Mas a primeira pessoa não precisa seguir esta via para obter conhecimento da própria crença.

Os estados mentais têm a peculiaridade de ter seu acesso restrito, ou seja, acesso privilegiado ao agente que o realiza. Com isso, ao que parece é permitido afirmar, ao seguir uma visão do senso comum, que "eu simplesmente tenho ciência ou consciência de meus pensamentos e sensações." (MASLIN, 2009, p. 27), verificação por meio de uma televisão ou espelho para saber o que o agente pensa ou sente não se faz necessária. 
Portanto, os estados mentais são particulares, em oposição ao público. O acesso privilegiado só é possível a cada agente que o realiza, ou seja, o acesso privilegiado aos próprios estados mentais é, como diz o nome, um privilégio do eu, da primeira pessoa. Logo, não se pode ter conhecimento dos estados mentais das outras pessoas via acesso privilegiado, tanto quanto os outros não podem ter acesso privilegiado dos estados mentais do agente. Com relação aos estados mentais, o acesso é privilegiado, ou seja, assimétrico, pois

(...) há uma diferença no acesso que outras pessoas têm aos conteúdos das minhas crenças e pensamentos, pois, enquanto eles precisam observar meu comportamento e interpretar minhas palavras, por outro lado, eu não preciso fazer isso. (SILVA FILHO, 2013, p. 33, n. 2)

Logo, conhecer meus próprios estados mentais por uma maneira típica de primeira pessoa é possível, porém não se pode saber o que o outro pensa da mesma maneira como o eu se conhece. $\mathrm{O}$ acesso privilegiado às outras mentes é negado. Para tornar mais tácito o ponto há a metáfora do besouro-numa-caixa, de Ludwig Wittgenstein. Tal metáfora consiste em cada um possui um besouro numa caixa, mas ninguém poder ter acesso ao besouro do outro. Dessa maneira, todos olham as próprias caixas, mas não sabem se os outros têm um besouro. Pode ocorrer que a referência de uma outra pessoa seja uma aranha, ou algo qualquer, entretanto nunca se descobrirá, pois o acesso é privilegiado. Tal processo ocorre análogo aos estados mentais, pois poderia ocorrer de "não haver qualia algum, mas meramente um deserto mental" (MASLIN, 2009, p. 27).

Assim, na visão do senso comum, o conhecimento das próprias crenças não necessita o emprego de órgãos dos sentidos (como olhos, ouvidos, etc.). O senso comum não diria que o eu é capaz de conhecer as próprias crenças ao olhar para fora - algo que é defendido por Gareth Evans (1982) e Richard Moran (2001). Neste sentido, o eu tem conhecimento da crença de maneira privilegiada, pois somente o eu sabe, sem o emprego dos sentidos, o que acredita. 


\section{Profundezas do Autoconhecimento}

Para conhecer as crenças dos outros, há observação envolvida. Porém para conhecer as próprias crenças, parece que não. A questão entorno da maneira de conhecer o próprio estado mental da crença dessa forma é considerada mais clara, na medida que se observa a questão do entendimento, ou seja, da "conectividade, construção de sentido, aplicação e justificação" (FERREIRA; EL-HANI; SILVA-FILHO, 2016 p. 6) sobre o conteúdo da própria crença e as implicações desse entendimento. Neste ponto, talvez, ocorra o afastamento do senso comum e, por conseguinte, imergindo em questões do anti-individualismo com enfoque no conteúdo mental. Portanto, o autoconhecimento depende em parte do conhecimento do mundo no entorno do agente, contrariamente ao senso comum acerca do autoconhecimento, o qual não estabelece ligação do autoconhecimento com o mundo externo ao agente.

Porém, o ceticismo sugere a seguinte questão: será que o agente racional possui mesmo conhecimento das próprias crenças? Em uma análise rápida, conforme o caminho do senso comum, afirma-se que sim. Contudo, quando o agente pensa "acredito que acredito que estou escrevendo em meu notebook e escutando uma música" (trata-se de um pensamento de segunda ordem, sobre uma crença de primeira ordem, "acredito que estou escrevendo em meu notebook e escutando uma música"), o agente tem clareza sobre todos os conteúdos do estado mental? Parece que sim, pois entendo muito bem o que é escrever, o que é um notebook e o que é uma música. No entanto, o agente se auto atribui outra crença: "creio que otorrinolaringologia é a área da medicina que estuda as doenças dos pés". Há o acesso privilegiado a essa crença, pois o "acesso" é sem o emprego da observação via sentidos. Entretanto, em um segundo momento, ao pesquisar a palavra "otorrinolaringologia" num bom dicionário, o agente verifica que estava equivocado quanto ao significado do conteúdo no uso comum da língua portuguesa brasileira. Ou seja, apesar do acesso privilegiado, parece que não está correto o emprego do conceito. 


\section{Características do autoconhecimento}

Até agora se descreveu o que sejam estados corporais, mentais, atitudes proposicionais e autoconhecimento de crenças. Destacou-se algumas diferenças entre essas noções, e agora cabe, nesta seção, ressaltar algumas características do autoconhecimento.

O que se entende pela noção de autoconhecimento? Conforme Gertler, o "Autoconhecimento é o conhecimento de seus próprios estados mentais - por exemplo, o conhecimento que alguém tem de suas próprias experiências, pensamentos, crenças ou desejos correntes." (GERTLER, 2011, p. 2). Dessa forma, ao expressar uma crença, por exemplo, "S acredita que p", essa atribuição de crença pode conter uma ou mais das sete características abaixo, a saber:

a) autoridade de primeira pessoa, consistindo em se afirmar que quando uma pessoa expressa um estado mental, ela está em melhor posição do que os outros para fazer a autoatribuição do estado mental, e normalmente tem autoridade reconhecida pelos outros para tal;

b) caráter apriorístico, ou seja, não há necessidade de investigação empírica, ou de realizar inferências, para se saber que se está em determinado estado mental intencional;

c) capacidade cognitivo-discriminativa, consistindo na capacidade de uma pessoa de estabelecer diferenças e semelhanças entre estados mentais iguais e diferentes; isto é, os conteúdos expressos nos estados mentais são entendidos pelo sujeito;

d) infalibilidade, desta forma as auto atribuições dos estados mentais de primeira pessoa atuais são incorrigíveis quanto a sua descrição;

e) onisciência, é que cada estado mental é necessariamente conhecido pelo agente que o formula;

f) assimetria entre a primeira e a terceira pessoa, a qual consiste na diferença do acesso que tenho aos meus próprios estados mentais e o acesso que os outros têm aos meus estados mentais, os quais necessitam de observação para tal, e eu não; e

g) impossibilidade do uso equivocado do pronome "eu", ou seja, uma pessoa em seu estado mental normal não comete erro de identificação ao usar o termo referencial "eu". (SILVA FILHO, 2013, p. 33, n. 2) 
De acordo com as posições usuais no debate acerca do conhecimento das próprias crenças, há dois tipos de acesso de um agente ou sujeito aos próprios estados mentais, o acesso direto e outro indireto. Se, um agente tem acesso direto às suas próprias crenças, então tipicamente não necessita da inferência, interpretação ou evidência para conhecer as próprias crenças. Se, por exemplo, o agente autoatribui a seguinte crença, "eu acredito que não vai chover agora", o que se dá é que o agente não necessita de algum intermediário, na forma de uma evidência conscientemente considerada, ou de uma premissa explicitamente endossada, para realizar a autoatribuição. Porém, se o agente tem acesso indireto as próprias crenças, então o acesso do agente a própria crença ocorre por via de inferência, de maneira interpretativa ou pela consideração de alguma evidência. Por exemplo, o agente afirma "vai chover hoje", e raciocina: "se eu afirmo que vai chover hoje, então eu creio que vai chover hoje". Desse modo, ele chega ao conhecimento da própria crença de maneira indireta.

\section{Crenças como disposições e crenças como compromisso}

No decorrer da vida, formula-se diversas crenças, como "creio que os seres humanos são bons por natureza", "eu acredito que irá chover agora", "eu acredito que o Grêmio será campeão", entre outras. O vocabulário proposto por Annalisa Coliva (2016) auxilia a distinção entre as crenças como disposições e as crenças como compromissos ${ }^{40}$. Pois, considera o autoconhecimento das crenças atuais, sua constituição pode ser de forma deliberada ou simplesmente com o acesso as crenças existentes, por exemplo, quando se questiona sobre qual a raiz

$40 \quad$ Clássica conceituação de crenças disposicionais, a saber. "Uma afirmação disposicional é uma afirmação, não sobre qualquer coisa que esteja realmente ocorrendo no momento, mas sim que alguma coisa em particular é propensa a ocorrer, sob certas circunstâncias. (...) Suponha que Harry pense que os laços xadrez são horríveis. Apenas raramente o pensamento ou julgamento de que eles são hediondos realmente vem à tona de sua mente. Quando isso acontece, ele possui a crença ocorrendo. O resto do tempo, Harry possui a crença apenas de forma disposicional. A crença existente vem e vai, dependendo de se as circunstâncias a provocam; a crença disposicional perdura." (SCHWITZGEBEL, 2015, p. 10) 
quadrada de 144, a resposta não faz parte de uma análise de evidências do mundo para se chegar a tal crença. Essa definição se afasta da noção tradicional de disposicional enquanto ocorrente. Assim, as crenças disposicionais se caracterizam da seguinte maneira:

(a) esses estados mentais não são o resultado de uma deliberação consciente, como um julgamento, da parte de um sujeito, baseada na consideração e, em particular, na avaliação (ou mesmo ser capaz de avaliar) de evidências a favor de P (ou de $\mathrm{P}$ vale a pena perseguir, seria bom se $\mathrm{P}$ acontecesse, etc.);

(b) esses estados mentais não estão dentro do controle direto de alguém, sendo antes algo como um fardo para o sujeito;

(c) portanto, o sujeito não é considerado racionalmente responsável por esses estados mentais. (COLIVA, 2016, p. 28)

$\mathrm{O}$ agente possui muitos estados mentais do tipo crença disposicional, no sentido de Coliva. Entretanto, não chega a tais crenças por deliberação própria. Quando o agente crê disposicionalmente, no sentido de Coliva, aquilo que ele crê não é o resultado ou conclusão de um processo racional cuidadosamente controlado. Assim, quando o sujeito crê disposicionalmente, no sentido de Coliva, o agente não é racionalmente responsável pela sua crença, pois não chegou à crença através de um processo racional. Por exemplo, o agente crê que as duas linhas de um teste Müller-Lyer parecem não ter o mesmo comprimento.

Ao contrário, os estados mentais por compromisso são diferentes dos disposicionais no sentido de Coliva:

(a') que eles são o resultado de uma ação - a ação mental de julgar que P é o caso (ou algo que vale a pena buscar/ter) da parte do sujeito, com base na consideração e, portanto, na avaliação da evidência para P (como algo que vale a pena buscar/ter);

(b) que esses estados mentais são (pelo menos) restritos normativamente - ou seja, devem responder aos princípios que governam o raciocínio teórico e prático;

(c') e, em particular, elas são tão restritas (também) do ponto de vista do sujeito;

(d') que eles são estados mentais pelos quais o sujeito é considerado racionalmente responsável. (COLIVA, 2016, p. 31-32) 
Tais estados mentais de crença por comprometimento são deliberados pelo agente epistêmico, ou seja, ele se posiciona - de acordo com normas racionais - perante uma evidência, a qual ele avalia como indicativo de que algo é ou não é o caso. Consequentemente, na formação da crença como compromisso, o agente epistêmico segue certas normas racionais, e com isso assumi responsabilidade racional acerca dos estados mentais. Por exemplo, "eu acredito que não irá chover hoje". Se, ao olhar para fora, o agente verifica o céu nublado, isso leva-o a persistir na crença que ele formula. Logo, existe dois tipos de estados mentais do tipo crença: os disposicionais e os de comprometimento.

\section{Novamente o anti-individualismo}

Uma posição contrária ao anti-individualismo (segundo o qual o conhecimento dos estados mentais depende em parte do conhecimento do mundo ao entorno) é que os conteúdos mentais são intrassubjetivos, isto é, são internos ao agente. Para o agente constituir o estado mental "eu tenho artrite na coxa", ele tem de investigar a própria mente a tese que cada um conhece os próprios estados mentais por introspecção, sem necessitar investigar seu entorno, no exemplo, sem investigar a própria sensação da artrite na coxa. Algo que parece estranho devido a imediaticidade das próprias sensações, tal como a dor, a qual não necessita de intermediários, como, a introspecção.

Outra questão sobre o exemplo anterior merece resposta, a saber, o agente que afirma "eu tenho artrite na coxa" usa corretamente os conteúdos e significados para constituir seu estado mental? Para Dummett,

É uma característica inegável da noção de significado - uma noção tão obscura - que o significado é transparente no sentido que, se alguém atribui um significado a uma entre duas palavras, ele deve conhecer se esses significados são os mesmos. (DUMMETT, 1978, p. 131 apud SILVA FILHO, 2013, p. 37-38) 
Dummett não usa a noção de transparência no mesmo sentido de Evans (1982) e Moran (2001). Para Dummett, é razoável afirmar que, enquanto agentes falantes, existe a capacidade de verificar a semelhança e diferença entre dois significados ou estados mentais. Assim, o agente deve ser capaz de estabelecer a distinção ou semelhança entre duas ocorrências de estados mentais:

(...) posso desconhecer o valor de verdade de meus pensamentos (por exemplo, que esteja aqui, sentado ao pé do fogo, vestido com um roupão, tendo este papel entre as mãos'), não seu conteúdo (que é isso, e não outra coisa, que estou pensando). (FARIA, 2001, p. 117 apud SILVA FILHO, 2013, p. 39)

Na visão de Dummett, não se pode saber quais são os pensamentos verdadeiros ou falsos próprios do eu. Contudo, não se pode afirmar desconhecer que tipo de estado mental ocorre, assim como o conteúdo semântico.

\section{Considerações finais}

A autoatribuição de estados mentais doxásticos do agente racional possui diversas características. Elas são: autoridade de primeira pessoa, caráter apriorístico, capacidade cognitivo-discriminativa, transparência dos conteúdos, infalibilidade, onisciência, assimetria entre primeira e terceira pessoa e impossibilidade do uso equivocados do pronome "eu". Também há o acesso direto e privilegiado às suas crenças, de forma não inferencial e não se pode errar quanto a autoatribuição do estado mental. Logo, o autoconhecimento de crenças se denota diverso do senso comum.

Portanto, destaca-se que o conhecimento do conteúdo semântico e a sua diferenciação de outros estados mentais estão de posse do agente, ou seja, o agente epistêmico sabe, mesmo que desconheça seu valor de verdade. Por conseguinte, conforme Coliva (2016) a responsabilidade epistêmica reside no comprometimento do agente para com sua crença. $\mathrm{O}$ agente racional pode ter responsabilidade epistêmica sobre a autoatribuição (seja verdadeira ou falsa) de crença (crença enquanto 
comprometimento), assim como não possuir responsabilidade epistêmica sobre ela (crença enquanto disposição).

\section{Referências:}

BONJOUR, L.; BAKER, A. Mentes e corpos. In: BONJOUR, L.; BAKER, A. (Eds.). Filosofia: textos fundamentais comentados. 2. ed. Porto Alegre: Artmed, 2010. p. 199-205.

COLIVA, A. The Varieties of self-knowledge. London: Palgrave Macmillan, 2016.

DESCARTES, R. Meditações. In: Os pensadores. Tradução de J. Guinsburg e Bento Prado Júnior. 3a ed., São Paulo; Abril Cultural, 1983.

DUMMETT, M. Frege‘s Distinction between Sense and Reference. In: . Truth and other Enigmas. Cambridge, MA: Harvard University Press, 1978. p. 116-144.

EVANS, G. The Varieties of Reference. Ed. John McDowell. Oxford: Oxford UniversityPress, 1982.

FARIA, p. Discriminação e conhecimento de si. In: PINHEIRO, W.; RUFFINO, M.; SMITH, P.J. (Org.). Ontologia, conhecimento e linguagem. Rio de Janeiro: Mauad, 2001. p. 113-128.

FERREIRA, T. A. S.; EL-HANI, C. N.; SILVA-FILHO, W. J. DA. Knowledge, Belief, and Science Education. In: Science \& Education, 2016. Acessado em 31 de maio de 2019. Disponível em:<https://philarchive.org/archive/SILKBA > .

GERTLER, B. Self-knowledge. London, New York: Routledge, 2011. KLEIN, S. What memory is. In: WIREs Cognitive Science, Vol. 6, Issue 1, January/February, 2015. p. 1-38. Acessado em 17 de agosto de 2019. Disponível em: <https://onlinelibrary.wiley.com/doi/ abs/10.1002/wcs.1333>.

HUME, D. Tratado da natureza humana. Tradução de Déborah Danowski. 2. ed. São Paulo: Editora UNESP, 2009.

MASLIN, K. T. Introdução à filosofia da mente. Tradução de Fernando José R. da Rocha. 2. ed. Porto Alegre: Artmed, 2009.

MORAN, R. Authority and estrangement: an essay on self-knowledge. Princeton: Princeton University Press, 2001.

OLIVEIRA, G. S. Estados mentais e atitudes proposicionais: Abordagens filosóficas da psicologia do senso comum. Dissertação de Mestrado. São Paulo: Universidade de São Paulo, 2014.

RUSSELL, B. The Philosophy of Logical Atomism. London and New York: Routledge, 2009. Disponível em: < https://sites.ualberta. 
ca/ francisp/NewPhil448/RussellPhilLogicalAtomismPears.pdf $>$. Acessado em 25 de novembro de 2018.

SENJU, A.; SOUTHGATE, V.; SNAPE, C.; LEONARD, M.; CSIBRA, G. Do 18-month-olds really attribute mental states to others? A critical test. Psychological Science, 22. 2011, pgs. 878-880. Disponível em:<https://www.ncbi.nlm.nih.gov/pmc/articles/PMC3799747/>. Acessado em 20 de dezembro de 2018.

SILVA FILHO, W. J. Sem ideias claras e distintas. Salvador: EDUFBA, 2013.

SCHWITZGEBEL, E. Self-ignorance. In: Consciousness and the Self. New essays. Edited by Jeeloo Liu and John Perry. Cambridge: Cambridge University Press, 2012, p. 184-197.

SCHWITZGEBEL, E. Belief. The Stanford Encyclopedia of Philosophy. Edward N. Zalta (ed.).

Stanford: Stanford University, 2015. Disponível em: <http://plato. stanford.edu/archives/sum2015/entries/belief/ > . Acessado em 27 de novembro de 2016. 
